\title{
A Proposed Classification of ICD-11 Severity Degrees of Personality Pathology Using the Self and Interpersonal Functioning Scale
}

\section{OPEN ACCESS}

Edited by:

Antonella Somma,

Vita-Salute San Raffaele

University, Italy

Reviewed by:

Hilario Blasco-Fontecilla,

Puerta de Hierro University Hospital,

Spain

Liliana Lorettu,

University of Sassari, Italy

*Correspondence:

Dominick Gamache

dominick.gamache@uqtr.ca

Specialty section:

This article was submitted to

Psychopathology,

a section of the journal

Frontiers in Psychiatry

Received: 10 November 2020 Accepted: 19 February 2021

Published: 18 March 2021

Citation:

Gamache D, Savard C, Leclerc P.

Payant M, Berthelot N, Côté A, Faucher J, Lampron M, Lemieux R

Mayrand K, Nolin M-C and

Tremblay M (2021) A Proposed Classification of ICD-11 Severity

Degrees of Personality Pathology

Using the Self and Interpersonal

Functioning Scale.

Front. Psychiatry 12:628057.

doi: 10.3389/fpsyt.2021.628057

\begin{abstract}
Dominick Gamache ${ }^{1 *}$, Claudia Savard ${ }^{2}$, Philippe Leclerc ${ }^{1}$, Maude Payant ${ }^{3}$, Nicolas Berthelot ${ }^{4}$, Alexandre Côté ${ }^{1}$, Jonathan Faucher ${ }^{1}$, Mireille Lampron ${ }^{5}$, Roxanne Lemieux ${ }^{4}$, Kristel Mayrand ${ }^{5}$, Marie-Chloé Nolin ${ }^{1}$ and Marc Tremblay ${ }^{6}$

${ }^{1}$ Department of Psychology, Université du Québec à Trois-Rivières, Trois-Rivières, QC, Canada, ${ }^{2}$ Department of Educational Fundamentals and Practices, Université Laval, Quebec City, QC, Canada, ${ }^{3}$ Department of Psychology, Université du Québec à Montréal, Montreal, QC, Canada, ${ }^{4}$ Department of Nursing Sciences, Université du Québec à Trois-Rivières, Trois-Rivières, QC, Canada, ${ }^{5}$ School of Psychology, Université Laval, Quebec City, QC, Canada, ${ }^{6}$ Centre intégré universitaire de santé et de services sociaux de la Capitale-Nationale, Quebec City, QC, Canada
\end{abstract}

Background: The 11th version of the World Health Organization's International Classification of Diseases (ICD-11) has adopted a dimensional approach to personality disorder (PD) nosology. Notably, it includes an assessment of PD degree of severity, which can be classified according to five categories. To date, there is no gold standard measure for assessing degree of PD severity based on the ICD-11 model, and there are no empirically-based anchor points to delineate the proposed categories. With the operationalization of PD degrees of severity in the ICD-11 PD model now being closely aligned with Criterion A of the DSM-5 Alternative Model for Personality Disorders (AMPD), sharing a focus on self and interpersonal dysfunction, self-report instruments developed for the latter model might prove useful as screening tools to determine degrees of severity in the former.

Methods: The Self and Interpersonal Functioning Scale, a brief validated self-report questionnaire originally designed to assess level of personality pathology according to the AMPD framework, was used to derive anchor points to delineate the five severity degrees from the ICD-11 PD model. Data from five clinical and non-clinical samples (total $N=2,240$ ) allowed identifying anchor points for classification, based on Receiver Operating Characteristic curve analysis, Latent Class Analysis, and data distribution statistics. Categories were validated using multiple indices pertaining to externalizing and internalizing symptoms relevant to PD.

Results: Analyses yielded the following anchor points for PD degrees of severity: No PD = 0-1.04; Personality Difficulty = 1.05-1.29; Mild PD = 1.30-1.89; Moderate $\mathrm{PD}=1.90-2.49 ;$ and Severe $\mathrm{PD}=2.50$ and above. A clear gradient of severity across the five categories was observed in all samples. A high number of significant contrasts among PD categories were also observed on external variables, consistent with the ICD-11 PD degree of severity operationalization.

Conclusions: The present study provides potentially useful guidelines to determine severity of personality pathology based on the ICD-11 model. The use of a brief 
self-report questionnaire as a screening tool for assessing PD degrees of severity should be seen as a time-efficient support for clinical decision and treatment planning.

Keywords: personality disorder, ICD-11 classification of personality disorders, dimensional models of personality disorders, degree of severity, self and interpersonal dysfunction

\section{INTRODUCTION}

The field of personality disorders (PDs) is moving decisively toward a dimensional conceptualization of personality pathology. Shortcomings of the traditional, categorical method for PD classification have been well-documented [e.g., excessive comorbidity among disorders, heterogeneity within each category, inadequate coverage of PD presentations with an overreliance on "Not otherwise specified" diagnosis, lack of validity of diagnostic categories; e.g., $(1,2)]$. It is widely believed that the adoption of a dimensional model of PDs will address these issues, and that a dimensional framework is more consistent with available empirical evidence on the nature of these disorders [e.g., (3-5)].

While calls for moving the field toward a dimensional paradigm are not new [e.g., (6-8)], it is only recently that changes have actually been implemented in the most recent versions of both the Diagnostic and Statistical Manual for Mental Disorders (DSM) and the International Classification of Diseases (ICD). An Alternative Model for Personality Disorders (AMPD) was introduced in Section III of the fifth edition of the DSM (9); it was meant to replace the traditional categorical PD model but was ultimately relegated to Section III by the APA Board of Trustees, awaiting further research. The AMPD includes two main components. Criterion A was proposed as an indicator of the level of personality pathology severity; it includes four elements that are believed to be closely intertwined and focus on impairments in one's sense of self (Identity and Self-direction) and in interpersonal relationships [Empathy and Intimacy; (10)]. Criterion B includes 25 maladaptive personality traits hierarchically organized into five broader domains [Negative Affectivity, Detachment, Antagonism, Disinhibition, and Psychoticism; (11)]. The model also retains six specific personality disorders that can be diagnosed based on "algorithms"; in these algorithms, the presence of two or more Criterion A elements and of Criterion B traits specific to each disorder is necessary for PD diagnosis, making the AMDP a hybrid categorical-dimensional model. Research on the AMPD has burgeoned over the past years and has yielded very promising results [see (12) for a summary].

For its part, the eleventh version of the World Health Organization's (WHO) International Classification of Diseases (ICD-11) has resolutely adopted a dimensional approach to PD nosology [see (4) for a detailed timeline of the different steps that led to the final proposal]. The purpose of the new model was "to provide a classification that was easily understood, could be readily used by practitioners of all disciplines, and that allowed all people with personality disturbance to be recognized" [(4), p. 497]. In the retained model, PD is defined as a marked disturbance in personality functioning, leading to considerable personal and social disruption in most cases. The central manifestations of PD are impairments in self-functioning (e.g., identity, self-worth, self-direction) and/or problems in interpersonal functioning (e.g., developing and maintaining close and mutually satisfying relationships, understanding others' perspectives, managing conflict). Both may manifest in maladaptive (e.g., inflexible, dysregulated) patterns of cognition, affective experience and expression, and behavior. PD can be classified according to a gradient of severity, ranging from (a) "No Personality Disorder," (b) "Personality Difficulty," (c) "Mild Personality Disorder," (d) "Moderate Personality Disorder," to (e) "Severe Personality Disorder" $(13,14)$. Table 1 summarizes the main differences among the different degrees of severity. The PD diagnosis may also be specified using one or more "Trait domain qualifiers" (Negative Affectivity, Detachment, Dissociality, Disinhibition, and Anankastia); an additional qualifier for Borderline Pattern may also be used. Of note, initial proposals for ICD-11 PDs did not focus on self and interpersonal dysfunction to define degree of severity, and were more closely aligned with the "British zeitgeist" of PD (15) in which personality pathology tends to be associated with potential of harm to self and others; they also did not include the Borderline specifier. It is only after some vocal opposition was expressed (16) that the initial proposal was amended.

Previous research has repeatedly shown that the global degree of PD severity, which will be the focus of this study, predicts a number of negative outcomes over and beyond PD categories. Indeed, general PD severity appears to be a strong predictor of current or future adjustment [e.g., (17-20)]. It also accounts for the comorbidity among categorical PD diagnoses (21) and appears to be sensitive to change (22). Moreover, it may provide valuable information for guiding intensity of clinical treatment [e.g., $(13,23)]$. To this day, however, empirical work aiming to operationalize the ICD-11 degrees of severity has been scarce, in contrast with the AMPD Criterion A for which multiple self-report and clinician-rated measures have been developed to assess level of PD severity [see $(24,25)$ for a summary]. One notable exception is the Standardized Assessment of Severity of Personality Disorder [SASPD; (26)], which was specifically developed to assess the ICD-11 severity of PD. It includes nine items pertaining to traits from each of the five ICD-11 trait model domains; respondents are asked about the impact of a particular problem (e.g., acting on impulse, worrying) on their risk of harm to self and others and on their interpersonal functioning. Initial psychometric evaluation of the SASPD revealed good predictive ability for determining mild and moderate personality disorder severity, and high test-retest stability (26). However, the SASPD was developed based on the initial ICD-11 proposal for PD, and 
TABLE 1 | Main differences among the ICD-11 degrees of severity for personality disorders.

\begin{tabular}{|c|c|c|c|}
\hline Personality difficulty & Mild personality disorder & Moderate personality disorder & Severe personality disorder \\
\hline $\begin{array}{l}\text { - Presence of personality } \\
\text { characteristics that may affect } \\
\text { treatment or health services but fall } \\
\text { short of a proper PD diagnosis. }\end{array}$ & $\begin{array}{l}\text { - Disturbances only affect some } \\
\text { areas of functioning of the self, or } \\
\text { affect all areas but are of mild severity. }\end{array}$ & $\begin{array}{l}\text { - Disturbances affect multiple areas of } \\
\text { functioning of the self and are of moderate } \\
\text { severity. }\end{array}$ & $\begin{array}{l}\text { - Severe disturbances in multiple } \\
\text { areas of functioning of the self. }\end{array}$ \\
\hline $\begin{array}{l}\text { - Difficulties are expressed only } \\
\text { intermittently or at a low level of } \\
\text { intensity. }\end{array}$ & $\begin{array}{l}\text { - Some problems are noted in } \\
\text { relationships or in performance/social } \\
\text { roles, but the individual is able to } \\
\text { maintain some of them. }\end{array}$ & $\begin{array}{l}\text { - Marked problems (e.g., conflict, } \\
\text { avoidance, extreme dependency) are } \\
\text { noted in most relationships, and } \\
\text { performance in most social/occupational } \\
\text { roles is affected to some degree. }\end{array}$ & $\begin{array}{l}\text { - Serious problems affect virtually all } \\
\text { relationships, and the individual is } \\
\text { unable or unwilling to perform } \\
\text { expected social and occupational } \\
\text { roles. }\end{array}$ \\
\hline $\begin{array}{l}\text { - Difficulties are insufficiently severe to } \\
\text { cause significant disruption in social, } \\
\text { occupational, and interpersonal } \\
\text { relationships or may be limited to } \\
\text { specific relationships/situations. }\end{array}$ & $\begin{array}{l}\text { - Not typically associated with } \\
\text { significant harm to self or others. } \\
\text { - May be associated with substantial } \\
\text { distress or with limited to } \\
\text { circumscribed impairment in } \\
\text { important areas of functioning. }\end{array}$ & $\begin{array}{l}\text { - Sometimes associated with harm to self } \\
\text { or others. } \\
\text { - Associated with marked impairment in } \\
\text { most important areas (although functioning } \\
\text { in circumscribed areas may be preserved). }\end{array}$ & $\begin{array}{l}\text { - Often associated with harm to self } \\
\text { or others. } \\
\text { - Associated with severe impairment } \\
\text { in all (or nearly all) important areas of } \\
\text { life. }\end{array}$ \\
\hline
\end{tabular}

Adapted from Bach and First (13) and World Health Organization (14). ICD-11, 11th revision of the International Classification of Diseases.

thus did not include elements pertaining to self and interpersonal deficits. In a comparative study of ICD-11 and DSM-5 Section III personality disorder models, McCabe and Widiger (27) found that the SASPD's convergence with the DSM-5 Section III model was improved when combined with the 12-item Level of Personality Functioning Scale-Brief Form [LPFS-BF; (28)], which assesses self and interpersonal impairments in line with the AMPD. McCabe and Widiger (27) concluded that the SASPD might benefit from a revision to include self and interpersonal deficits. In the same vein, in a study comparing the SASPD and the LPFS-BF in their relationships with external correlates, Bach and Anderson (15) outlined that the SASPD appeared to be more closely tied to the initial ICD-11 PD model, i.e., emphasizing risk of harm to self and others, while the LPFS-BF may have better sensitivity in detecting core personality disorder features (i.e., self and interpersonal pathology), which corresponds to the retained model. Furthermore, in a study of the psychometric properties of the SASPD in German non-clinical and clinical samples, Rek et al. (29) found mixed results for convergent and discriminant validity, calling into question its future usage as a screening tool of ICD-11-based degrees of PD severity.

These results, which highlight the potential shortcomings of the SASPD to capture essential features of the final ICD11 PD model, along with positive results obtained using a self-report initially aimed to operationalize the AMPD, suggest that measures of the latter model might be useful in assessing ICD-11 PD degrees of severity. This "cross walk" strategy was also advocated by Bach and First [(13), p. 6], who stressed that "diagnostic information obtained from assessment tools developed for the DSM-5 AMPD model can be used for making an ICD-11 dimensional Personality Disorder diagnosis." As aforementioned, there have been numerous self-report questionnaires developed to assess the AMPD that could be useful for that purpose (25). One of these instruments is the Self and Interpersonal Functioning Scale [SIFS; (30)], a 24-item measure originally developed based on the AMPD Criterion A conceptualization. It provides a global personality dysfunction score and four subscale scores, corresponding to AMPD elements (Identity, Self-direction, Empathy, and Intimacy). In its original validation study, meaningful patterns of associations with related psychological constructs (e.g., selfesteem, satisfaction with life, empathy, aggression, pathological narcissism, borderline symptomatology, and AMPD Criterion B domains) were reported. Confirmatory Factor Analysis yielded a second-order model, with four elements organized into a higherorder personality dysfunction factor, consistent with AMPD formulation. In an independent study, content validity analysis of the SIFS items also showed promising results, and the severity level assessed by its items makes it well-suited to study populations with greater psychopathology (25).

The purpose of the present study is to determine, based on the SIFS' global score (i.e., a general indicator of personality impairment), cutoff points corresponding to the five categories in the ICD-11 PD model. Although there might be some irony in "imposing" categories in a fundamentally dimensional framework (31), we believe that these categories are likely to provide clinicians and researchers with useful guidelines, e.g., for treatment planning and level of care assessment [e.g., $(13,23)]$. Furthermore, we concur with Rek et al. (29) that accessible and time-efficient PD screening tools are crucial in a context in which these pathologies are too often overlooked during assessment. Providing guidelines for a screening of PD severity based on a short and validated self-report measure such as the SIFS might be a valuable contribution in this regard.

\section{MATERIALS AND METHODS Participants and Procedure}

A total of 2,240 adults, mainly French-speaking Canadians, were recruited in the Province of Quebec, Canada (84.6\% women, $M_{\text {age }}=31.43, S D=8.66$, range $\left.18-79\right)$. They were recruited in five distinct samples. The first three correspond to clinical samples. Sample $1(n=287)$ includes prospective PD patients with a more severe clinical presentation, recruited during the 
intake procedure at a specialized psychiatric outpatient clinic in the Quebec City area. Sample $2(n=249)$ includes prospective PD patients with a less severe clinical presentation, who were also recruited during the intake procedure from different outpatient treatment establishments in the Quebec City area. Both settings are public, and have a mandate of treating PD patients; in line with a stepped care approach [e.g., see (32)], those with more severe clinical presentations are referred to the first clinic for more intensive treatment (Sample 1), while those with less severe presentations are referred to other establishments who offer PD treatment programs but with a less intensive level of care (Sample 2). Sample $3(n=242)$ includes patients from two general private practice clinics located in Quebec City; these clinics use a common set of intake measures as part of a collaborative study. The last two samples correspond to non-clinical participants. Sample $4(n=1,200)$ includes female participants from a study of pregnant women's mental health. They were recruited through advertisement on social media (Facebook and Instagram). Finally, Sample $5(n=263)$ includes participants from the community recruited as part of the initial validation study of the SIFS (30). They were recruited through social media, online message boards, and institutional e-mail from two universities in the Province of Quebec. Supplementary Table 1 provides more detail on sociodemographic characteristics of these five samples.

\section{Measures \\ Identification of Cutoffs for the ICD-11 PD Severity Degrees}

The Self and Interpersonal Functioning Scale (30), described above, was used in our main analyses to determine clinical cutoff points corresponding to the proposed ICD-11 anchors for PD severity, based on its global score (Cronbach's alpha $[\alpha]$ for the combined sample $=0.91$ ). Items are rated on a five-point scale (range 0-4). Descriptive statistics for all five samples are displayed in Supplementary Table 2.

\section{External Validation of Degrees of Severity}

Samples had different sets of self-report questionnaires, which were used in further analyses to validate the different anchor points established using the SIFS. Supplementary Table 2 displays the different questionnaires from each sample, along with their descriptive statistics (i.e., mean scores and internal consistency indices).

\section{Samples 1, 2, 3, and 5}

The Personality Inventory for DSM-5 was used in its 100item version, the PID-5 Faceted Brief Form [PID-5-FBF; (33); French validation by Roskam et al. (34)] for Samples 1, 3, and 5 , and in its 25-item version, the PID-5 Brief Form [PID-5$\mathrm{BF}]$; (35); French validation by Combaluzier et al. (36)] for Sample 2. It covers five domains of pathological personality functioning: Negative Affectivity, Detachment, Antagonism, Disinhibition, and Psychoticism. Items are rated on a four-point scale (range $0-3$ ).

\section{Samples 1 and 2}

The 23-item version of the Borderline Symptom List [BSL23; (37); French validation by Nicastro et al. (38)] assesses borderline PD symptomatology according to DSM Section II BPD diagnostic criteria, in addition to other affective experiences typical of borderline pathology (e.g., proneness to shame, selfcriticism, mistrustfulness). Items are scored on a five-point scale (range 0-4).

The 28-item Brief Version of the Pathological Narcissism Inventory [B-PNI; (39); French validation by Diguer et al. (40)] was used to measure two dimensions of pathological narcissism: Grandiosity (e.g., inflated self-image, exploitative behaviors, fantasies of power and perfection) and Vulnerability (e.g., depleted self-image, shame/anger, interpersonal hypersensitivity). Items are scored on a six-point scale (range 0-5).

\section{Sample 1 Only}

The 12-item short-form Buss-Perry Aggression Questionnaire [BPAQ-SF; (41, 42); French validation by Genoud and Zimmerman (43)] covers four manifestations of aggression: Verbal, Physical, Anger, and Hostility. It also yields a global Trait Aggression score. Items are scored on a six-point scale (range 1-6).

The 28-item Interpersonal Reactivity Index [IRI; (44); French validation by Gilet et al. (45)] measures empathy and its components. Two of its subscales were used in the present study: Perspective Taking (the ability to adopt others' point of view), which assesses the cognitive component of empathy, and Empathic Concern (the motivation to care about others), which focuses on the affective component. Items are scored on a seven-point scale (range 1-7).

The 30-item Barratt Impulsiveness Scale [BIS-11; (46); French validation by Baylé et al. (47)] is designed to assess three components of impulsiveness: Attentional, Motor, and Nonplanning. Items are scored on a four-point scale (range 1-4).

\section{Sample 3 Only}

The 14-item version of the Psychiatric Symptom Index [PSI; (48); French validation by Préville et al. (49)] covers core psychological symptoms (e.g., depression, anxiety, anger). Items are scored on a four-point scale (range $0-3$ ).

The shortened 12-item Experiences in Close Relationship Questionnaire [ECR-12; (50)] assesses both dimensions of romantic attachment: Anxiety about relationship issues, and Avoidance (discomfort with closeness and interdependence). Items are scored on a seven-point scale (range 1-7).

\section{Sample 4 Only}

The 10-item Kessler Psychological Distress Scale [K-10; (51) French validation by Gravel et al. (52)] assesses anxious and depressive symptomatology. Items are rated on a five-point scale (range 1-5).

The 10-item Edinburgh Perinatal/Postnatal Depression Scale [EPDS; (53) French validation by Adouard et al. (54)] indicates the presence of depressive symptoms during pregnancy and in 
the year following childbirth. Items are scored on a four-point scale (range 1-4).

The 20-item Positive and Negative Affect Schedule [PANAS; (55); French validation by Gaudreau et al. (56)] covers the experience of feelings such as energy, enthusiasm, and inspiration (Positive Affect), as well as experiences such as fear, hostility, and shame (Negative Affect). Items are scored on a five-point scale (range 1-5).

Two subscales of the Dissociative Experiences Scale [DES; (57); French validation by Larøi et al. (58)], Absorption/Imaginative involvement (nine items) and Depersonalization/Derealization (six items), were used. Items are rated on an 11-point scale (range $0-10$ ).

The 20-item Posttraumatic Stress Disorder (PTSD) Checklist for DSM-5 [PCL-5; (59); French validation by Ashbaugh et al. (60)] covers trauma-related symptoms aligned with the PTSD diagnostic criteria of the DSM-5. Items are rated on a five-point scale (range $0-4$ ).

\section{Sample 5 Only}

The 19-item brief version of the Inventory of Personality Organization (IPO) validated by Verreault et al. (61) includes three scales from the original IPO (62): Identity Diffusion, Primitive Defenses, and Impaired Reality Testing, along with a Global Personality Organization score. Items are scored on a five-point scale (range 1-5).

The five-item Satisfaction with Life Scale [SWLS; (63); French validation by Blais et al. (64)] uses straightforward probes about participants' life satisfaction. Items are scored on a seven-point scale (range 1-7).

The 10-item Rosenberg Self-Esteem Scale [RSES; (65); French validation by Vallières and Vallerand (66)] is a unidimensional measure of global self-esteem. Items are scored on a four-point scale (range 1-4).

\section{Analytic Strategy}

In a preliminary step, $t$-tests for independent samples were computed on the global SIFS score for men and women for each sample (with the exception of Sample 4 which only includes women), to rule out the need for separate cutoffs based on gender. The ensuing statistical analyses followed a four-step procedure. (a) The first step aimed at delineating participants with vs. without a personality disorder. This should establish a first threshold between the "No PD" and the "Personality Difficulty" groups, on the one hand, and the Mild-ModerateSevere PD groups, on the other hand. In order to do so, we ran a Receiver Operating Characteristic (ROC) curve analysis, combining Samples 1 and 2 (PD patients) to form a first dichotomous groups (with PD), and combining Samples 4 and 5 (pregnant women and participants from the community) to form a second dichotomous group (without PD) ${ }^{1}$. Sample 3,

\footnotetext{
${ }^{1}$ In practice, these two groups cannot be perfectly dichotomous and a small overlap between them is expected. On the one hand, a small part of the community sample probably has a diagnosable PD [in line with previous results from large-scale epidemiological studies; (67)]. On the other hand, this is most likely offset by the fact that patients referred for PD treatment might not always have PD proper; they might only display personality difficulty, and instances of misdiagnosis, although
}

recruited in private practice clinics, was excluded at this step, as the expected prevalence of PD in these clinical settings is uncertain. The ROC analysis allowed choosing a cutoff point to establish the presence of a PD; this cutoff was selected based on empirical considerations (i.e., optimal sensitivity-specificity based on Youden's index, Diagnostic odds ratio). It was also based on "clinical plausibility," as the retained cutoff should yield a PD prevalence in non-clinical groups in the range observed in past epidemiological studies conducted in community samples. While the range of these estimates is quite large, from 4.4 (68) to $33.1 \%$ (69), the selected cutoff should ideally yield prevalence indices close to the median estimate of $11.5 \%$, based on 14 major studies, reported by Morgan and Zimmerman (67).

(b) In a second step, delineation among the three categories where PD is present (Mild, Moderate, Severe) according to the ICD-11 model was established. This was computed using Latent Class Analysis (LCA) on the subsample of participants from all five samples identified as having a PD based on the threshold established in step (a). The SIFS total score was used as the sole latent indicator, and a predetermined number of three profiles was specified for the analysis. These profiles are thus expected to be established based on a gradient of severity; the Mild severity profile is expected to have more participants, while the Severe profile should have less, and the Moderate severity should be in between these two. Hallquist and Pilkonis (70), drawing on a previous work from Markon and Krueger (71), have commented on the potential use of LCA to determine severity degrees, suggesting that "when LCA supports the existence of two or more latent classes that differ by severity, the mean severity level for each class provides potential information about cut-points along a continuous severity dimension" (p. 229). Thus, means and standard deviations from the three profiles yielded by LCA were used to establish anchor points for the Mild, Moderate, and Severe categories.

(c) The third step involved delineating the "No PD" from the "Personality Difficulty" group. This latter group is defined in the ICD-11 PD model by the presence of long-standing difficulties in a person's way of experiencing and thinking about oneself, others, and the world; in contrast to PD proper, however, individuals with Personality Difficulty only show intermittent, or low intensity, manifestations of these difficulties in the cognitive, emotional, or behavioral domains (14). Thus, individuals with Personality Difficulty might be expected to be found in prospective patients referred to PD clinical programs in Samples 1 and 2, but who did not reach the diagnostic threshold for a PD. The delineation between No PD and Personality Difficulty was based on mean and standard deviation (i.e., within $\leq 1.0 S D$ ) for these individuals.

(d) Finally, once anchor points were established for all five PD and non-PD categories, the last step involved their validation based on a set of external variables relevant for PD and general psychosocial functioning. The five samples included different sets of mostly non-overlapping self-report measures, tailored to their clinical context (e.g., more measures

rare, cannot be excluded (e.g., Disorders due to substance use or Bipolar type II disorder mimicking PD symptomatology). 
of externalizing pathology and potential for harm in the most severe samples). These measures should provide a wide range of clinical and functioning variables for validation. Samples were tested separately, using Kruskall-Wallis analysis (twotailed, with Bonferroni's correction for multiple comparisons) to contrast categories, as the number of participants per category was likely to show marked differences. In Samples 1 and 2, the "No PD" category was omitted from analyses as it was expected to have a very low prevalence in these groups ${ }^{2}$. The same goes for the "Severe PD" group in Samples 3, 4, and 5. Valid PD severity categories would be expected to show a gradient of severity (i.e., minimal pathology in the No PD group, and maximal pathology in the Severe group, with increments between intermediate categories). Contrasts between contiguous/consecutive categories (e.g., between No PD and Personality Difficulty, or between Moderate and Severe PD) were considered a stringent test of the discriminative power of the cutoffs established through steps (a) to (c).

\section{RESULTS}

In a preliminary step, gender differences for the SIFS total score were ruled out for each sample: Sample $1=M_{\text {women }}=1.89, S D$ $=0.62 ; M_{\text {men }}=1.92, S D=0.58 ; t_{(285)}=-0.48, p=0.63$; Sample $2=M_{\text {women }}=1.66, S D=0.61 ; M_{\text {men }}=1.75, S D=0.56 ; t_{(246)}$ $=-1.18, p=0.24$; Sample $3=M_{\text {women }}=1.09, S D=0.52 ; M_{\text {men }}$ $=1.19, S D=0.60 ; t_{(240)}=-1.29, p=0.20$; Sample $5=M_{\text {women }}$ $=0.97, S D=0.48 ; M_{\text {men }}=1.01, S D=0.50 ; t_{(261)}=-0.57, p=$ 0.57 . These results allowed determining common cutoffs for men and women in the ensuing analytic steps.

\section{Delineation Between Participants With vs. Without PD}

ROC analysis was performed using the SIFS total score as predictor of belonging to a PD group (Samples 1 and 2) vs. a nonclinical group (Samples 4 and 5; see Figure 1). Area under the curve was 0.90 (CI [0.88-0.92], $S E=0.01$ ), an excellent accuracy with a large effect size $(d=1.84)$ according to established guidelines (72). Based on aforementioned criteria for cutoff selection, we chose 1.31 (rounded to 1.30 ; Sensitivity $=0.79$, Specificity $=0.86$, Diagnostic odds ratio $=23.23$ ) as the cutoff between PD and absence of PD. This anchor point yielded the following prevalence for PD in our five samples: Sample $1=$ $82.2 \%$; Sample $2=71.3 \%$; Sample $3=32.6 \%$; Sample $4=11.2 \%$; Sample $5=22.4 \%$.

\section{Delineation Among the Mild, Moderate, and Severe PD Groups Based on Degree of Severity}

LCA was run using Mplus version 8.4 (73) on participants $(n=$ 713 ) with a PD according to the 1.30 cutoff established in step (a), with the standardized SIFS total score as the profiling variable,

\footnotetext{
${ }^{2}$ Absence of personality difficulty, at the very least, is implausible in these samples. Indeed, all patients from Samples 1 and 2 were referred to their respective clinics after a categorical PD diagnosis, or at least presence of pathological personality traits, was established by a psychiatrist or a general practitioner.
}

forcing the analysis to extract three classes from data. The entropy figure (0.81) suggested an adequate classification according to usual guidelines (a score between 0.8 and 1.0 is generally considered adequate). The three classes, Mild, Moderate, and Severe PD, included, respectively, 439 (61.6\%; $M=1.59, S D=$ $0.17), 213$ (29.9\%; $M=2.18, S D=0.18)$, and $61(8.6 \% ; M=2.84$, $S D=0.23)$ participants.

Using SIFS means and standard deviations of roughly $+/-1.5$ units for the three classes generated by LCA, the following anchor points were established for the three degrees of PD severity: Mild $=1.30-1.89$; Moderate $=1.90-2.49$; Severe $=2.50$ and above (see Table 2).

\section{Delineating Absence of PD From Personality Difficulty}

Using the subsample of patients from Samples 1 and 2 who did not reach the threshold for $\mathrm{PD}(n=123)$, we computed their mean SIFS score $(M=1.29, S D=0.26)$ to determine the cutoff for Absence of PD vs. Personality Difficulty. Using an estimate of 1.0 SD, the final threshold between these two categories was established at 1.03 (rounded to 1.05); therefore, the Personality Difficulty anchor points correspond to 1.05-1.29 (see Table 2).

In sum, the final thresholds, corresponding to ICD-11 PD degree of severity categories and based on SIFS total score, are as follows: Absence of PD $=0$ to 1.04; Personality Difficulty $=1.05$ to 1.29 ; Mild $\mathrm{PD}=1.30$ to 1.89 ; Moderate $\mathrm{PD}=1.90$ to 2.49; and Severe PD $=2.50$ and above. Table 2 shows how participants from the five samples included in the present study are distributed along the five categories.

\section{Validation of Categories With External Variables}

Tables 3-7 display, for each sample, how participants from the five ICD-11 degree of severity categories differ across a number of external validation indices. Intergroup differences for the SIFS total score and elements are also presented but will not be considered as "external" comparators in the following analyzes as the ICD-11 categories are not statistically independent from these indices. A general pattern of results emerged in all five samples, as a clear gradient of severity across the five ICD-11 categories was observed. A high number of significant contrasts among PD categories were also observed.

In the most severe sample (Sample 1), there was a remarkably neat break between the Mild and Moderate categories, as significant differences were observed for 16 out of 18 comparisons. There was also a clear delineation between the Moderate and Severe categories, with 13 out of 18 contrasts yielding significant results. Fewer differences (two) were observed between the Personality Difficulty vs. Mild categories. Of note, two comparators (PID-5 Disinhibition and BIS-11 Motor impulsivity) showed a high discriminant capacity, with significant differences across all four ICD-11 categories tested in that sample (see Table 3). The other PD sample (Sample 2) showed a similar pattern of results, with a clear gradient of severity across PD severity categories for all external variables, although less significant contrasts between contiguous categories 
were observed: four out of eight for Personality Difficulty vs. Mild PD (PID-5 Disinhibition and Psychoticism, PNI Grandiosity and Vulnerability), three out of eight for Mild vs. Moderate PD (PID5 Negative Affectivity and Detachment, PNI Vulnerability), and one out of eight for Moderate vs. Severe PD (BSL-23 Borderline symptoms; see Table 4).

Comparisons for Samples 3 to 5 did not include the Severe PD category. Again, the expected pattern of increased severity was observed across degrees of severity. In the private practice sample

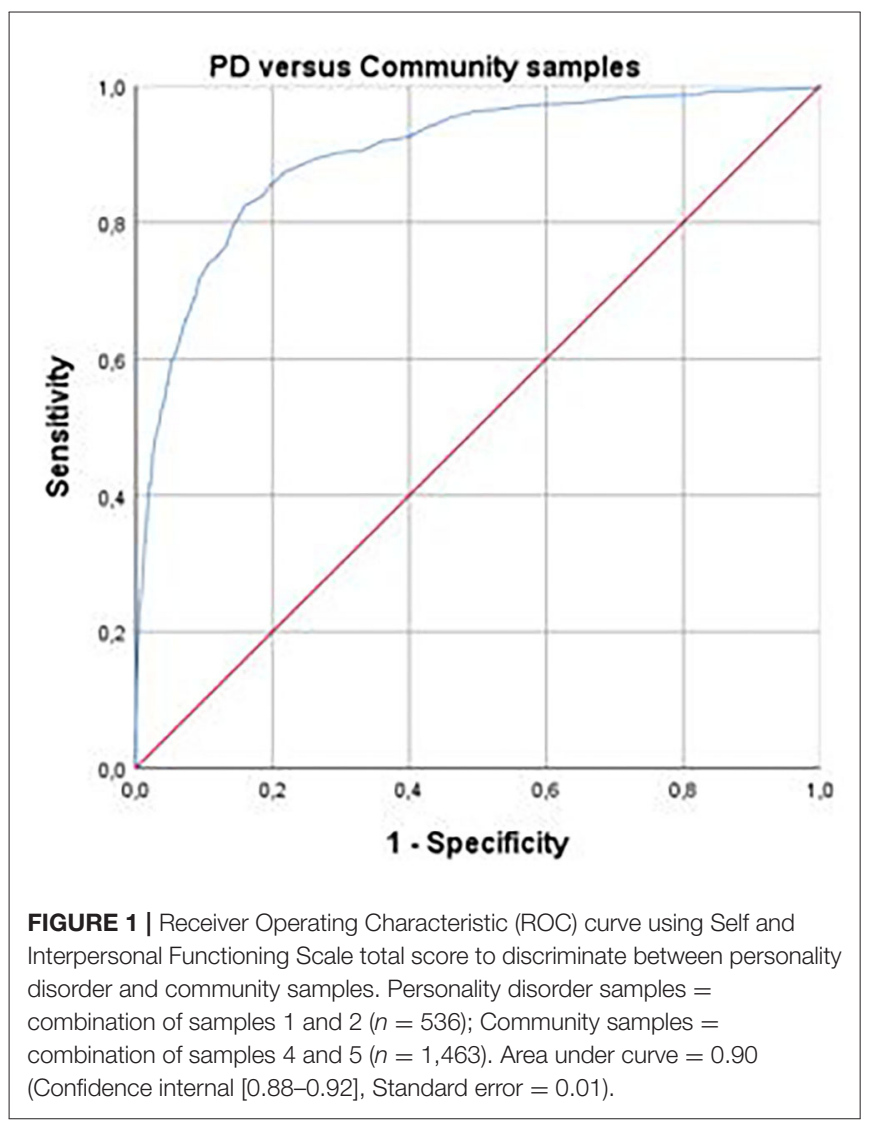

(Sample 3), the following significant contrasts were observed for contiguous categories: two out of eight for No PD vs. Personal difficulty (PID-5 Detachment; PSI symptoms); none between Personality Difficulty and Mild PD, and also none between Mild and Moderate PD. Of note, ECR-12 attachment avoidance did not show any significant difference across degrees of severity (see Table 5). In Sample 4 (pregnant women from the community), significant contrasts for contiguous categories were as follows: six out of seven for No PD vs. Personality Difficulty (K-10 psychological symptoms; EPDS depression; PANAS Negative Affect; DES Absorption and Derealization; PCL-5 trauma); five out of seven between Personality Difficulty and Mild PD (K10 psychological symptoms; EPDS depression; DES Absorption and Depersonalization; PCL-5 trauma); and none between Mild and Moderate PD (see Table 6). Finally, for Sample 5, significant contrasts for contiguous categories were as follows: six out of 13 for No PD vs. Personality Difficulty (PID-5 Negative Affectivity; IPO Global Personality Organization, Identity Diffusion, and Primitive Defenses; SWLS Satisfaction with life; and RSES Selfesteem); one out of 13 between Personality Difficulties and Mild PD (SWLS Satisfaction with life); and three out of 13 between Mild and Moderate PD (PID-5 Psychoticism; IPO Reality Testing; RSES Self-esteem). IRI Empathic Concern had no discriminant power to distinguish PD degrees of severity (see Table 7).

\section{DISCUSSION}

The aim of the present study was to propose an empirically-based classification of the five ICD-11 PD degrees of severity based on the SIFS, a self-report questionnaire that was originally developed to operationalize the level of functioning criterion from the DSM-5 AMPD. Across five clinical and non-clinical samples, we found consistent support for a graduated classification of severity, based on the five categories from the ICD-11 PD model, which range from "No PD" to "Severe PD." Results tend to support the validity of the proposed anchor points, which were based on the SIFS' total score. They also substantiate the suggestion that diagnostic information from instruments originally developed for Criterion A of the DSM-5

TABLE 2 | Distribution of participants from the five samples according to ICD-11 degrees of severity thresholds established with the Self and Interpersonal Functioning Scale total score.

\begin{tabular}{|c|c|c|c|c|c|c|}
\hline Category & SIFS score range & \multicolumn{3}{|c|}{ Clinical samples } & \multicolumn{2}{|c|}{ Non-clinical samples } \\
\hline No PD & $0-1.04$ & $24(8.4 \%)$ & 32 (12.9\%) & $124(51.2 \%)$ & 927 (77.3\%) & $150(57.0 \%)$ \\
\hline Personality difficulty & $1.05-1.29$ & $21(7.3 \%)$ & 35 (14.1\%) & $33(13.6 \%)$ & $128(10.7 \%)$ & $53(20.2 \%)$ \\
\hline Mild PD & $1.30-1.89$ & $100(34.8 \%)$ & 95 (38.2\%) & $64(26.4 \%)$ & $126(10.5 \%)$ & 45 (17.1\%) \\
\hline Severe PD & 2.50 and above & 44 (15.3\%) & 25 (10.0\%) & $6(2.5 \%)$ & $1(0.1 \%)$ & $2(0.8 \%)$ \\
\hline
\end{tabular}

ICD-11, 11th revision of the International Classification of Diseases; SIFS, Self and Interpersonal Functioning Scale; PD, Personality disorder; Sample 1, Specialized psychiatric

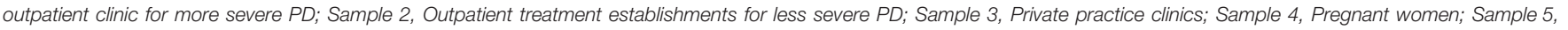
Community participants. 
TABLE 3 | Comparisons among the ICD-11 personality disorders degrees of severity on external variables for sample 1 (specialized clinic for more severe personality disorders).

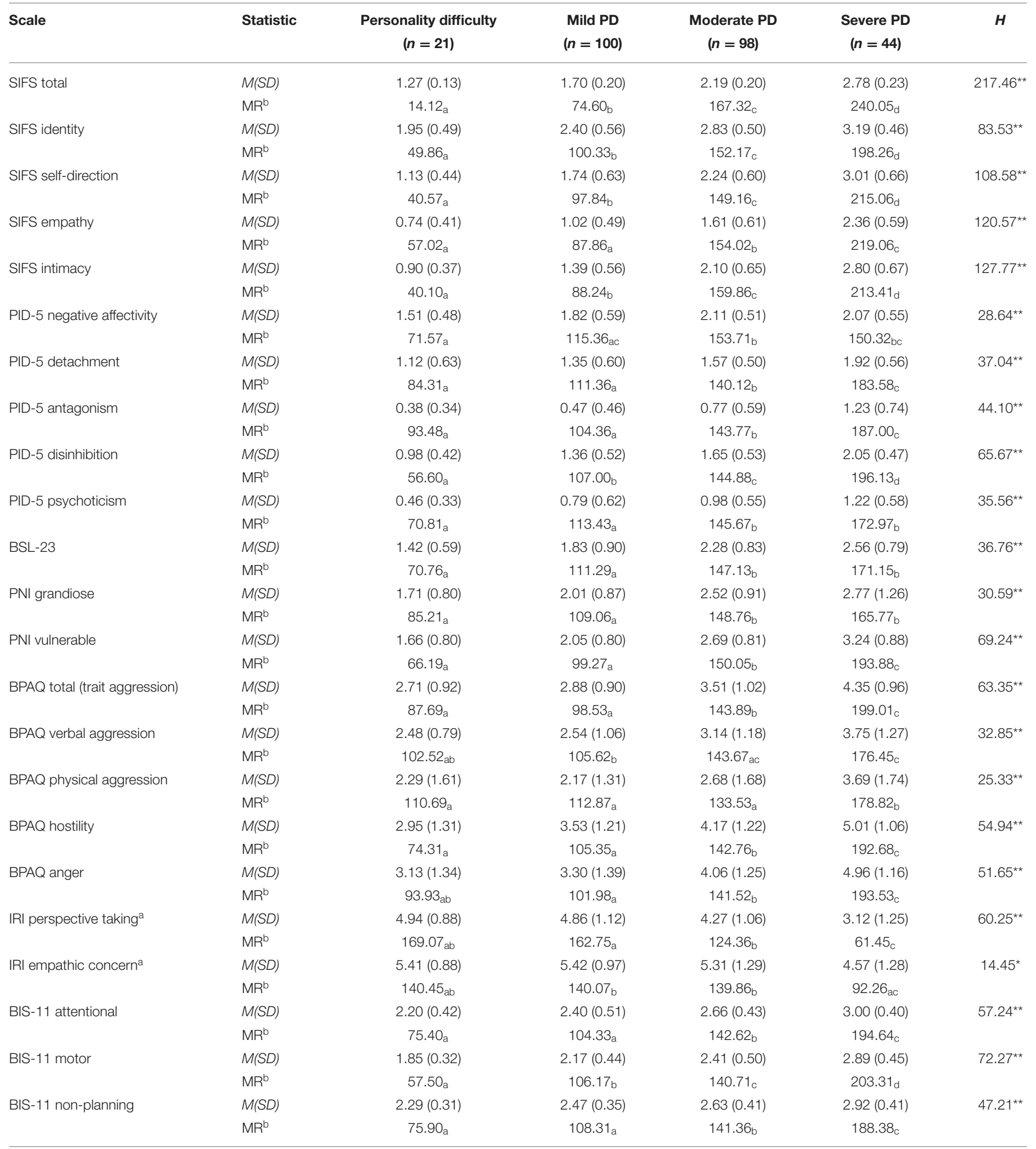

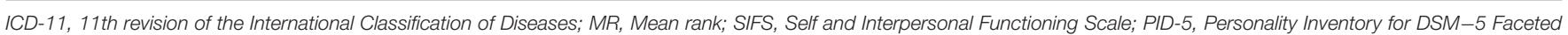

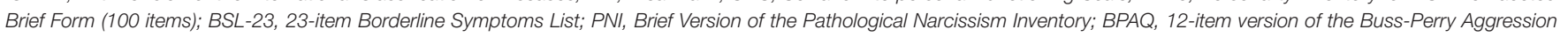
Questionnaire; IRI, Interpersonal Reactivity Index; BIS-11, Barratt Impulsiveness Scale (version 11).

a Higher scores denote better functioning. For all other variables, higher scores denote more severe pathology.

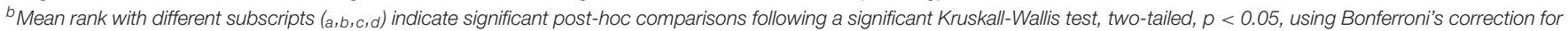
multiple comparisons.

${ }^{*} p<0.01 ;{ }^{* *} p<0.001$. 
TABLE 4 | Comparisons among the ICD-11 personality disorders degrees of severity on external variables for sample 2 (specialized clinic for less severe personality disorders).

\begin{tabular}{|c|c|c|c|c|c|c|}
\hline Scale & Statistic & $\begin{array}{l}\text { Personality difficulty } \\
\qquad(n=35)\end{array}$ & $\begin{array}{l}\text { Mild PD } \\
(n=95)\end{array}$ & $\begin{array}{c}\text { Moderate PD } \\
(n=62)\end{array}$ & $\begin{array}{c}\text { Severe PD } \\
(n=25)\end{array}$ & $H$ \\
\hline \multirow[t]{2}{*}{ SIFS total } & $M(S D)$ & $1.17(0.08)$ & $1.61(0.16)$ & $2.15(0.15)$ & $2.80(0.22)$ & $191.76^{\star \star}$ \\
\hline & $\mathrm{MR}^{\mathrm{a}}$ & $18.00_{a}$ & $83.00_{b}$ & $161.59_{\mathrm{C}}$ & $205.00_{d}$ & \\
\hline \multirow[t]{2}{*}{ SIFS identity } & $M(S D)$ & $1.82(0.49)$ & $2.40(0.53)$ & $2.84(0.49)$ & $3.23(0.43)$ & $89.47^{\star \star}$ \\
\hline & $\mathrm{MR}^{\mathrm{a}}$ & $42.90_{a}$ & $94.62_{b}$ & $141.02_{C}$ & $176.76_{c}$ & \\
\hline \multirow[t]{2}{*}{ SIFS self-direction } & $M(S D)$ & $1.34(0.52)$ & $1.78(0.62)$ & $2.24(0.64)$ & $2.94(0.64)$ & $75.00^{\star \star}$ \\
\hline & $\mathrm{MR}^{\mathrm{a}}$ & $55.83_{a}$ & $93.87 b$ & $132.06_{c}$ & $183.88_{d}$ & \\
\hline \multirow[t]{2}{*}{ SIFS empathy } & $M(S D)$ & $0.67(0.34)$ & $1.13(0.49)$ & $1.58(0.56)$ & $2.45(0.63)$ & $98.47^{\star \star}$ \\
\hline & $\mathrm{MR}^{\mathrm{a}}$ & $42.97 \mathrm{a}$ & $93.81_{b}$ & $137.03_{C}$ & $189.66_{d}$ & \\
\hline \multirow[t]{2}{*}{ SIFS intimacy } & $M(S D)$ & $0.82(0.43)$ & $1.10(0.58)$ & $1.89(0.50)$ & $2.54(0.64)$ & $109.17^{\star \star}$ \\
\hline & $\mathrm{MR}^{\mathrm{a}}$ & $55.17 \mathrm{a}$ & $81.52 \mathrm{a}$ & $150.26 b$ & $186.60_{b}$ & \\
\hline \multirow[t]{2}{*}{ PID-5 negative affectivity } & $M(S D)$ & $1.51(0.59)$ & $1.70(0.56)$ & $1.95(0.53)$ & $2.22(0.46)$ & $30.05^{\star \star}$ \\
\hline & $\mathrm{MR}^{\mathrm{a}}$ & $79.01_{a}$ & $96.68_{a}$ & $126.29 b$ & $154.90_{b}$ & \\
\hline \multirow[t]{2}{*}{ PID-5 detachment } & $M(S D)$ & $0.80(0.50)$ & $1.05(0.61)$ & $1.43(0.51)$ & $1.86(0.53)$ & $53.22^{\star \star}$ \\
\hline & $\mathrm{MR}^{\mathrm{a}}$ & $67.60_{a}$ & $93.12_{a}$ & $132.58_{b}$ & $168.84_{b}$ & \\
\hline \multirow[t]{2}{*}{ PID-5 antagonism } & $M(S D)$ & $0.49(0.45)$ & $0.67(0.60)$ & $0.90(0.58)$ & $1.17(0.54)$ & $26.16^{\star \star}$ \\
\hline & $\mathrm{MR}^{\mathrm{a}}$ & $80.51_{a b}$ & $97.20_{a b}$ & $124.02_{b c}$ & $151.68_{c}$ & \\
\hline \multirow[t]{2}{*}{ PID-5 disinhibition } & $M(S D)$ & $0.83(0.41)$ & $1.16(0.48)$ & $1.36(0.57)$ & $1.67(0.65)$ & $34.57^{\star \star}$ \\
\hline & $\mathrm{MR}^{\mathrm{a}}$ & $63.34 a$ & $104.01_{b}$ & $126.05_{b c}$ & $149.62_{C}$ & \\
\hline \multirow[t]{2}{*}{ PID-5 psychoticism } & $M(S D)$ & $0.73(0.44)$ & $1.13(0.57)$ & $1.22(0.55)$ & $1.61(0.73)$ & $27.60^{\star \star}$ \\
\hline & $\mathrm{MR}^{\mathrm{a}}$ & $66.09_{a}$ & $108.15_{b}$ & $119.07 \mathrm{bc}$ & $147.54_{C}$ & \\
\hline \multirow[t]{2}{*}{ BSL-23 } & $M(S D)$ & 1.39 (0.78) & $1.80(0.84)$ & $1.94(0.89)$ & $2.69(0.76)$ & $32.32^{\star \star}$ \\
\hline & $\mathrm{MR}^{\mathrm{a}}$ & $73.84 a$ & $102.84 \mathrm{ab}$ & $115.82_{b}$ & $164.72_{c}$ & \\
\hline \multirow[t]{2}{*}{ PNI grandiose } & $M(S D)$ & $1.71(0.86)$ & $2.28(0.80)$ & $2.44(0.76)$ & $2.42(0.81)$ & $16.75^{\star}$ \\
\hline & $\mathrm{MR}^{\mathrm{a}}$ & $70.50_{a}$ & $111.98_{b}$ & $120.28_{b}$ & $123.60_{b}$ & \\
\hline \multirow[t]{2}{*}{ PNI vulnerable } & $M(S D)$ & 1.63 (0.79) & $2.24(0.67)$ & $2.78(0.72)$ & $3.11(0.84)$ & $59.15^{\star \star}$ \\
\hline & $\mathrm{MR}^{\mathrm{a}}$ & $55.16 \mathrm{a}$ & $96.48_{b}$ & $138.25_{c}$ & $159.42_{C}$ & \\
\hline
\end{tabular}

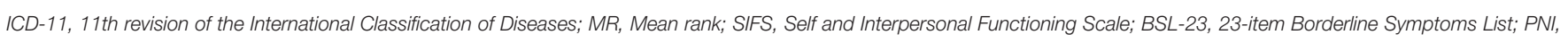
Brief Version of the Pathological Narcissism Inventory; PID-5, Personality Inventory for DSM-5 Brief Form (25 items).

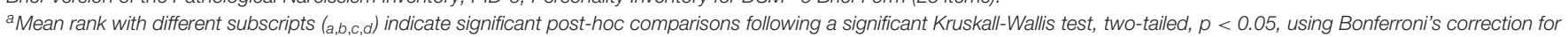
multiple comparisons.

${ }^{\star} p<0.01 ;{ }^{* *} p<0.001$.

AMPD model can be used with confidence for the ICD11 PD model's severity classification (13). More generally, our findings also constitute further evidence that general PD severity is a strong predictor of current symptomatology and distress [e.g., $(19,20)]$.

Prevalence of PD (i.e., as indicated by a score falling within the Mild, Moderate, or Severe PD categories) was very high in PD samples (84.3 and $73.0 \%$ ), as expected. The prevalence in private practice was $35.1 \%$, with very few participants in the Moderate or Severe categories. This is consistent with the fact that getting treatment in private practice, because of the costs incurred, most generally requires at least some capacity to maintain a source of revenue and thus to be able to sustain employment, which is a characteristic of Mild PD in contrast with the two most severe categories in the ICD-11 model (14). Prevalence in community participants was $12.1 \%$ in the sample of pregnant women, and $22.8 \%$ in the community sample collected for initial validation of the SIFS; in both cases, severe cases were extremely rare $(<1 \%)$. The prevalence for the latter sample, while falling within the range (4.4-33.1\%) of previous epidemiological studies on PD prevalence, is still noticeably higher than the median of $11.5 \%$ reported in a recent review of 14 large-scale studies (67). This result might be partially explained by a self-selection bias, as participants from Sample 5 were aware that they were contributing to a study aiming to validate a self-report pertaining to personality functioning; this may have inadvertently attracted participants with personality issues. Nonetheless, these figures are both in a plausible range, which supports the validity of the proposed cutoff between PD and absence of PD. In addition, results from the ROC curve analysis strengthen findings regarding the validity of the SIFS, which showed an excellent capacity to classify participants from PD groups vs. community samples.

External validation of the five categories from the ICD-11 PD model showed a clear gradient of severity, in all samples, and for virtually all the tested variables; a high number of meaningful differences, both from a statistical and a clinical standpoint, were found. The most striking differences were 
TABLE 5 | Comparisons among the ICD-11 personality disorders degrees of severity on external variables for sample 3 (private practice clinics).

\begin{tabular}{|c|c|c|c|c|c|c|}
\hline Scale & Statistic & $\begin{array}{c}\text { No PD } \\
(n=124)\end{array}$ & $\begin{array}{l}\text { Personality difficulty } \\
\qquad(n=33)\end{array}$ & $\begin{array}{l}\text { Mild PD } \\
(n=64)\end{array}$ & $\begin{array}{c}\text { Moderate PD } \\
(n=15)\end{array}$ & $H$ \\
\hline \multirow[t]{2}{*}{ SIFS total } & $M(S D)$ & $0.70(0.20)$ & 1.17 (0.08) & $1.56(0.17)$ & $2.13(0.13)$ & 195.70* \\
\hline & $\mathrm{MR}^{\mathrm{a}}$ & $62.50_{a}$ & $141.00_{b}$ & $185.50_{c}$ & $229.00_{c}$ & \\
\hline \multirow[t]{2}{*}{ SIFS identity } & $M(S D)$ & $1.11(0.51)$ & $1.79(0.54)$ & $2.17(0.66)$ & $2.80(0.48)$ & $116.57^{\star}$ \\
\hline & $\mathrm{MR}^{\mathrm{a}}$ & $75.31_{a}$ & $140.58_{b}$ & $168.77_{b c}$ & $212.47_{C}$ & \\
\hline \multirow[t]{2}{*}{ SIFS self-direction } & $M(S D)$ & $0.83(0.45)$ & $1.41(0.39)$ & $1.71(0.72)$ & $2.25(0.77)$ & $93.30^{*}$ \\
\hline & $\mathrm{MR}^{\mathrm{a}}$ & $79.20_{a}$ & $145.91_{b}$ & $161.99_{b}$ & $197.59_{b}$ & \\
\hline \multirow[t]{2}{*}{ SIFS empathy } & $M(S D)$ & $0.43(0.30)$ & $0.78(0.46)$ & $1.08(0.54)$ & $1.70(0.52)$ & $98.95^{\star}$ \\
\hline & $\mathrm{MR}^{\mathrm{a}}$ & $79.83_{a}$ & $132.44_{b}$ & $164.70_{b c}$ & $210.37_{c}$ & \\
\hline \multirow[t]{2}{*}{ SIFS intimacy } & $M(S D)$ & $0.40(0.29)$ & $0.72(0.33)$ & $1.25(0.58)$ & $1.74(0.70)$ & $113.11^{*}$ \\
\hline & $\mathrm{MR}^{\mathrm{a}}$ & $77.04 \mathrm{a}$ & $127.33_{b}$ & $174.68_{c}$ & $202.07_{c}$ & \\
\hline \multirow[t]{2}{*}{ PID-5 negative affectivity } & $M(S D)$ & $0.95(0.49)$ & $1.19(0.57)$ & $1.49(0.56)$ & $1.71(0.57)$ & $47.07^{\star}$ \\
\hline & $\mathrm{MR}^{\mathrm{a}}$ & $90.96 a$ & $117.96 \mathrm{ab}$ & $151.67 \mathrm{bc}$ & $174.74_{C}$ & \\
\hline \multirow[t]{2}{*}{ PID-5 detachment } & $M(S D)$ & $0.37(0.31)$ & $0.67(0.48)$ & $0.85(0.42)$ & $1.29(0.53)$ & $74.68^{\star}$ \\
\hline & $\mathrm{MR}^{\mathrm{a}}$ & $83.06 \mathrm{a}$ & $126.81_{b}$ & $158.04 b c$ & $195.11_{c}$ & \\
\hline \multirow[t]{2}{*}{ PID-5 antagonism } & $M(S D)$ & $0.42(0.36)$ & $0.34(0.30)$ & $0.58(0.48)$ & $0.76(0.51)$ & $13.21^{*}$ \\
\hline & $\mathrm{MR}^{\mathrm{a}}$ & $110.48_{a}$ & $99.16 \mathrm{a}$ & $131.25_{\mathrm{ab}}$ & $157.74_{b}$ & \\
\hline \multirow[t]{2}{*}{ PID-5 disinhibition } & $M(S D)$ & $0.68(0.44)$ & $0.89(0.46)$ & $1.14(0.54)$ & $1.43(0.71)$ & $39.67^{\star}$ \\
\hline & $\mathrm{MR}^{\mathrm{a}}$ & $92.65_{a}$ & $120.97 \mathrm{ab}$ & $145.23_{b}$ & $169.63 b$ & \\
\hline \multirow[t]{2}{*}{ PID-5 psychoticism } & $M(S D)$ & $0.24(0.29)$ & $0.34(0.42)$ & $0.47(0.39)$ & $0.71(0.59)$ & $26.23^{\star}$ \\
\hline & $\mathrm{MR}^{\mathrm{a}}$ & $98.42_{a}$ & $115.23_{a b}$ & $144.10_{b}$ & $158.79_{b}$ & \\
\hline \multirow[t]{2}{*}{ PSI total } & $M(S D)$ & $0.86(0.42)$ & $1.15(0.46)$ & $1.36(0.61)$ & $1.64(0.54)$ & $50.76^{\star}$ \\
\hline & $\mathrm{MR}^{\mathrm{a}}$ & $88.72_{a}$ & $128.28_{b}$ & $147.95_{b c}$ & $180.53_{C}$ & \\
\hline \multirow[t]{2}{*}{ ECR anxiety } & $M(S D)$ & 3.59 (1.23) & $4.19(1.30)$ & $4.84(1.21)$ & $4.50(1.72)$ & $37.92^{\star}$ \\
\hline & $\mathrm{MR}^{\mathrm{a}}$ & $92.15_{a}$ & $120.50_{a b}$ & $155.74 \mathrm{bc}$ & $136.53_{\mathrm{abc}}$ & \\
\hline ECR avoidance & $M(S D)^{\mathrm{b}}$ & $2.48(1.08)$ & $2.90(1.22)$ & $2.81(1.11)$ & $2.76(0.96)$ & 4.92 \\
\hline
\end{tabular}

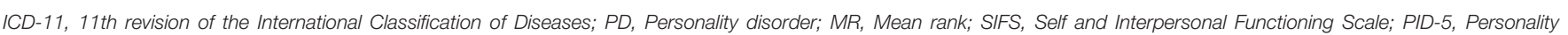

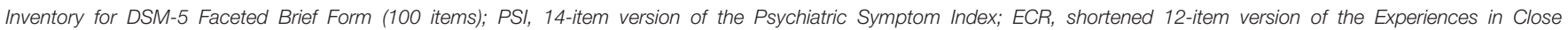
Relationships questionnaire.

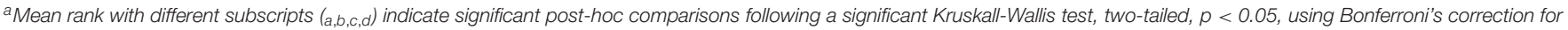
multiple comparisons.

${ }^{b}$ Mean rank not shown in the absence of significant contrasts.

${ }^{*} p<0.001$.

found in the most severe sample (Sample 1), as there was a very clear delineation among the Mild, Moderate, and Severe categories. These differences were very apparent on external variables reflective of externalizing pathology, notably aggression and impulsivity. This is especially important to support the validity of our classification, as the ICD-11 PD model stresses that the risk of harm to self and others is an important distinction among degrees of severity. It also supports the hypothesis from members of the ICD-11 PD Working Group, which was initially formulated about the borderline PD diagnosis specifically, "that individuals with mild personality disorder will display largely negative affective symptoms, whereas those with more severe disturbance will also have disinhibited and dissocial behaviors [emphasis added]" [(4), p. 495]. It also mitigates potential concerns regarding the SIFS' capacity for discrimination based on those variables, as the instrument was primarily developed to assess self and interpersonal dysfunction based on the AMPD model. In non-clinical samples, the most apparent distinctions were observed in Sample 4 (pregnant women), with the cleanest break being observed between the Personality Difficulty and
Mild PD degrees; as measures in that sample mostly focused on internalizing pathology (e.g., depression, trauma, negative affectivity, dissociation), these results highlight the SIFS' capacity to discriminate among degrees of severity based on personal distress, which is key to discriminate between Personality Difficulty (where distress is expected to be transient or of low intensity) and Mild PD (where distress may be substantial) in the ICD-11 PD model.

However, it should be noted that the SIFS' capacity for finegrained discrimination among severity degrees, as measured by the presence of statistically significant differences between contiguous categories, was uneven across samples. Interestingly, the scale's discriminant capacity was at its best in the most severe sample of PD patients (see Table 3), which supports Waugh et al.'s (25) conclusion that the SIFS seems more pathology-focused, and showed a lower discriminant capacity in the private practice sample (see Table 5). One possible-and intriguing-possibility is that "isomorphism" between structural personality deficits assessed by degree of severity measures and external correlates reflective of externalizing and/or internalizing 
TABLE 6 | Comparisons among the ICD-11 personality disorders degrees of severity on external variables for sample 4 (pregnant women).

\begin{tabular}{|c|c|c|c|c|c|c|}
\hline Scale & Statistic & $\begin{array}{c}\text { No PD } \\
(n=927)\end{array}$ & $\begin{array}{l}\text { Personality difficulty } \\
\qquad(n=128)\end{array}$ & $\begin{array}{l}\text { Mild PD } \\
(n=126)\end{array}$ & $\begin{array}{c}\text { Moderate PD } \\
(n=18)\end{array}$ & $H$ \\
\hline \multirow[t]{2}{*}{ SIFS total } & $M(S D)$ & $0.61(0.23)$ & $1.14(0.08)$ & $1.54(0.16)$ & $2.11(0.16)$ & $642.23^{\star}$ \\
\hline & $\mathrm{MR}^{\mathrm{b}}$ & $464.00_{a}$ & $991.50_{b}$ & $1118.50_{b c}$ & $1190.50_{c}$ & \\
\hline \multirow[t]{2}{*}{ SIFS identity } & $M(S D)$ & $0.86(0.38)$ & $1.39(0.38)$ & $1.97(0.47)$ & $2.11(0.51)$ & $436.61^{*}$ \\
\hline & $\mathrm{MR}^{\mathrm{b}}$ & $490.39_{a}$ & $865.25_{b}$ & $1056.89_{b c}$ & $1090.28_{c}$ & \\
\hline \multirow[t]{2}{*}{ SIFS self-direction } & $M(S D)$ & $0.78(0.43)$ & $1.37(0.49)$ & $1.68(0.51)$ & $2.04(0.60)$ & $355.76^{*}$ \\
\hline & $\mathrm{MR}^{\mathrm{b}}$ & $500.30_{a}$ & $862.90_{b}$ & $998.84 b c$ & $1073.19_{C}$ & \\
\hline \multirow[t]{2}{*}{ SIFS empathy } & $M(S D)$ & $0.46(0.33)$ & $0.93(0.39)$ & $1.28(0.49)$ & $2.15(0.57)$ & $392.89^{*}$ \\
\hline & $\mathrm{MR}^{\mathrm{b}}$ & $496.08 \mathrm{a}$ & $867.75_{b}$ & $1041.38_{C}$ & $1168.14_{C}$ & \\
\hline \multirow[t]{2}{*}{ SIFS intimacy } & $M(S D)$ & $0.37(0.31)$ & $0.89(0.43)$ & $1.25(0.53)$ & $2.13(0.45)$ & $394.87^{*}$ \\
\hline & $\mathrm{MR}^{\mathrm{b}}$ & $495.48 a$ & $876.46_{b}$ & $1095.87_{c}$ & $1175.67_{C}$ & \\
\hline \multirow[t]{2}{*}{$\mathrm{K}-10$} & $M(S D)$ & $2.00(0.64)$ & $2.33(0.60)$ & $2.70(0.63)$ & $2.83(0.56)$ & $157.00^{*}$ \\
\hline & $\mathrm{MR}^{\mathrm{b}}$ & $519.43 a$ & $697.26 b$ & $872.00_{c}$ & $945.06_{c}$ & \\
\hline \multirow[t]{2}{*}{ EPDS } & $M(S D)$ & $1.82(0.46)$ & $2.13(0.49)$ & $2.35(0.52)$ & $2.48(0.41)$ & $149.60^{*}$ \\
\hline & $\mathrm{MR}^{\mathrm{b}}$ & $524.27 \mathrm{a}$ & $722.01_{b}$ & $851.15_{c}$ & $942.08 \mathrm{bc}$ & \\
\hline \multirow[t]{2}{*}{ PANAS positive affect ${ }^{a}$} & $M(S D)$ & $2.81(0.62)$ & $2.70(0.58)$ & $2.61(0.58)$ & $2.48(0.41)$ & $18.03^{\star}$ \\
\hline & $\mathrm{MR}^{\mathrm{b}}$ & $595.40_{a}$ & $528.30_{a b}$ & $492.79_{b}$ & $380.47_{b}$ & \\
\hline \multirow[t]{2}{*}{ PANAS negative affect } & $M(S D)$ & $2.17(0.67)$ & $2.62(0.72)$ & $2.77(0.71)$ & $2.87(0.50)$ & $118.63^{*}$ \\
\hline & $\mathrm{MR}^{\mathrm{b}}$ & $523.55_{a}$ & $728.25_{b}$ & $802.84_{b}$ & $876.15_{b}$ & \\
\hline \multirow[t]{2}{*}{ DES absorption } & $M(S D)$ & $1.37(1.19)$ & $2.38(1.69)$ & 3.07 (1.89) & $3.45(1.88)$ & $155.98^{*}$ \\
\hline & $\mathrm{MR}^{\mathrm{b}}$ & $525.13_{a}$ & $716.34 b$ & $862.23_{c}$ & $937.00_{b c}$ & \\
\hline \multirow[t]{2}{*}{ DES depersonalization } & $M(S D)$ & $0.41(0.92)$ & $1.10(1.82)$ & $1.66(2.18)$ & $2.05(2.45)$ & $110.66^{*}$ \\
\hline & $\mathrm{MR}^{\mathrm{b}}$ & $542.43_{a}$ & $623.52_{b}$ & $813.52_{c}$ & $857.81_{b c}$ & \\
\hline \multirow[t]{2}{*}{ PCL-5 } & $M(S D)$ & $0.56(0.51)$ & $0.95(0.68)$ & 1.27 (0.68) & $1.34(0.57)$ & $174.68^{*}$ \\
\hline & $\mathrm{MR}^{\mathrm{b}}$ & $500.72 \mathrm{a}$ & $723.38_{b}$ & $860.57_{C}$ & $910.94 b c$ & \\
\hline
\end{tabular}

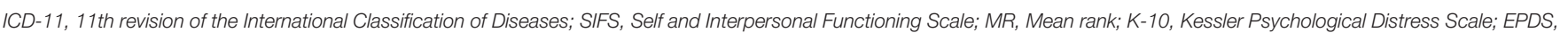

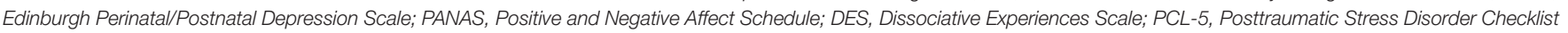
for DSM-5.

a Higher scores denote better functioning. For all other variables, higher scores denote more severe pathology.

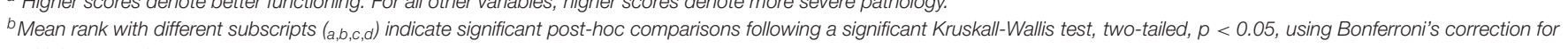
multiple comparisons.

${ }^{*} p<0.001$.

symptoms may be at its highest in clinical samples where patients are the most dysfunctional. In contrast, in private practice patients, there might be a more pronounced gap, as "structural" deficits may be present but with less apparent impact, which is notably reflected in a preserved ability to maintain employment, a prerequisite in most cases to afford psychotherapy in private settings. Other factors, such as issues pertaining to statistical power (with notable differences between group sizes to test for contrasts), also likely played a role.

The main limitation of the present study is the sole reliance on self-reported variables as external validators. While evidence supporting the validity and usefulness of self-ratings of personality pathology is mounting [e.g., $(74,75)]$, the impact of response style bias as a potential confounding variable could not be taken into account. Future investigations of the validity of the present degrees of severity should not only include multiple instruments, but also multiple methods, as well as longitudinal and behavioral outcomes assessment, most notably to assess the risk of harm to self and others. The lack of uniformity among batteries of measures in the different samples is also a noteworthy limitation, and hampers some potentially useful comparisons. Precise estimation of participants' ethnic background was unavailable, but data were collected in overwhelmingly Caucasian-white communities, which limits generalization of the findings, given than ethnicity has a well-documented impact on PD epidemiology [e.g., (76)]; this calls for inclusion of more diverse samples in future research. There was a significantly unbalanced male-female ratio in the total sample as well as across the four mixed-gender samples (1, 2,3 , and 5).

In sum, the present study provides potentially useful guidelines to determine severity of personality pathology based on the ICD-11 model, using a short self-report questionnaire, the Self and Interpersonal Functioning Scale. Results suggest that the SIFS total score can be used with confidence as a screening tool for provisional assessment of PD severity; it showed a strong capacity, in five independent samples, to classify patients in categories that were meaningfully associated with a number of indices of externalizing and internalizing symptomatology relevant to PD. The present study should be seen as a positive step in the validation of time-efficient, accessible, and cost-effective clinical strategies to overcome the 
TABLE 7 | Comparisons among the ICD-11 personality disorders degrees of severity on external variables for sample 5 (community participants).

\begin{tabular}{|c|c|c|c|c|c|c|}
\hline Scale & Statistic & $\begin{array}{c}\text { No PD } \\
(n=150)\end{array}$ & $\begin{array}{l}\text { Personality difficulty } \\
\qquad(n=53)\end{array}$ & $\begin{array}{l}\text { Mild PD } \\
(n=45)\end{array}$ & $\begin{array}{l}\text { Moderate PD } \\
\qquad(n=13)\end{array}$ & $H$ \\
\hline \multirow[t]{2}{*}{ SIFS total } & $M(S D)$ & $0.64(0.22)$ & $1.15(0.08)$ & $1.52(0.14)$ & $2.11(0.16)$ & $207.28^{\star \star}$ \\
\hline & $\mathrm{MR}^{\mathrm{b}}$ & $75.50_{a}$ & $177.50_{b}$ & $225.00_{C}$ & $255.00_{c}$ & \\
\hline \multirow[t]{2}{*}{ SIFS identity } & $M(S D)$ & $0.90(0.41)$ & $1.47(0.53)$ & $1.85(0.61)$ & $2.69(0.44)$ & $118.23^{\star *}$ \\
\hline & $\mathrm{MR}^{\mathrm{b}}$ & $90.04 a$ & $95.46 b$ & $162.74 \mathrm{bc}$ & $246.46_{c}$ & \\
\hline \multirow[t]{2}{*}{ SIFS self-direction } & $M(S D)$ & $0.83(0.44)$ & $1.28(0.40)$ & $1.60(0.56)$ & $1.94(0.62)$ & $91.94^{\star \star}$ \\
\hline & $\mathrm{MR}^{\mathrm{b}}$ & $94.38_{a}$ & $161.36_{b}$ & $191.82_{b}$ & $219.23_{b}$ & \\
\hline \multirow[t]{2}{*}{ SIFS empathy } & $M(S D)$ & $0.43(0.31)$ & $0.83(0.41)$ & $1.18(0.48)$ & $1.48(0.52)$ & $115.34^{\star *}$ \\
\hline & $\mathrm{MR}^{\mathrm{b}}$ & $90.71_{a}$ & $159.19_{b}$ & $205.44_{C}$ & $230.15_{c}$ & \\
\hline \multirow[t]{2}{*}{ SIFS intimacy } & $M(S D)$ & $0.45(0.39)$ & $1.01(0.48)$ & $1.43(0.56)$ & $2.21(0.45)$ & $129.33^{\star \star}$ \\
\hline & $\mathrm{MR}^{\mathrm{b}}$ & $88.02_{a}$ & $164.92_{\mathrm{a}}$ & $204.11_{b}$ & $245.92_{b}$ & \\
\hline \multirow[t]{2}{*}{ PID-5 negative affectivity } & $M(S D)$ & $0.88(0.47)$ & $1.24(0.59)$ & $1.49(0.61)$ & $1.72(0.52)$ & $71.71^{\star \star}$ \\
\hline & $\mathrm{MR}^{\mathrm{b}}$ & $87.25 a$ & $136.72_{b}$ & $165.72 \mathrm{bc}$ & $194.86_{c}$ & \\
\hline \multirow[t]{2}{*}{ PID-5 detachment } & $M(S D)$ & $0.36(0.34)$ & $0.68(0.43)$ & $1.02(0.47)$ & $1.59(0.18)$ & $95.51^{\star *}$ \\
\hline & $\mathrm{MR}^{\mathrm{b}}$ & $82.51 \mathrm{a}$ & $126.81_{b}$ & $165.85_{b}$ & $217.86_{c}$ & \\
\hline \multirow[t]{2}{*}{ PID-5 antagonism } & $M(S D)$ & $0.46(0.47)$ & $0.53(0.39)$ & $0.57(0.49)$ & $0.70(0.50)$ & $12.77^{\star \star}$ \\
\hline & $\mathrm{MR}^{\mathrm{b}}$ & $104.76_{a}$ & $126.80_{a b}$ & $140.26 b$ & $144.79_{\mathrm{ab}}$ & \\
\hline \multirow[t]{2}{*}{ PID-5 disinhibition } & $M(S D)$ & $0.63(0.43)$ & $0.90(0.52)$ & 1.09 (0.53) & $1.20(0.48)$ & $13.33^{\star \star}$ \\
\hline & $\mathrm{MR}^{\mathrm{b}}$ & $104.24 \mathrm{a}$ & $128.66 \mathrm{ab}$ & $139.95 b$ & $144.46 \mathrm{ab}$ & \\
\hline \multirow[t]{2}{*}{ PID-5 psychoticism } & $M(S D)$ & $0.20(0.29)$ & $0.31(0.33)$ & $0.46(0.51)$ & $0.92(0.60)$ & $35.76^{\star \star}$ \\
\hline & $\mathrm{MR}^{\mathrm{b}}$ & $98.73_{a}$ & $129.07 \mathrm{ab}$ & $139.13_{b}$ & $196.68_{c}$ & \\
\hline \multirow[t]{2}{*}{ IRI perspective taking a } & $M(S D)$ & $5.30(0.76)$ & $4.99(0.87)$ & $4.95(0.86)$ & $4.34(1.12)$ & $15.91^{*}$ \\
\hline & $\mathrm{MR}^{\mathrm{b}}$ & $138.60_{a}$ & $115.36_{a b}$ & $109.30_{a b}$ & $71.89_{b}$ & \\
\hline IRI empathic concern ${ }^{a}$ & $M(S D)^{\mathrm{C}}$ & $5.56(1.12)$ & $5.35(0.94)$ & $5.54(0.92)$ & $5.27(1.07)$ & 3.71 \\
\hline \multirow[t]{2}{*}{ IPO total } & $M(S D)$ & $1.54(0.27)$ & $1.77(0.33)$ & $2.02(0.45)$ & $2.32(0.55)$ & $74.05^{\star \star}$ \\
\hline & $\mathrm{MR}^{\mathrm{b}}$ & $93.46_{a}$ & $142.91_{b}$ & $185.12 \mathrm{bc}$ & $201.96_{C}$ & \\
\hline \multirow[t]{2}{*}{ IPO identity } & $M(S D)$ & $2.07(0.48)$ & $2.45(0.54)$ & $2.74(0.55)$ & $2.89(0.81)$ & $59.37^{\star \star}$ \\
\hline & $\mathrm{MR}^{\mathrm{b}}$ & $96.54 a$ & $143.55_{b}$ & $175.92_{b}$ & $185.32_{b}$ & \\
\hline \multirow[t]{2}{*}{ IPO defense mechanisms } & $M(S D)$ & $1.46(0.40)$ & 1.85 (0.58) & 2.10 (0.63) & $2.59(0.89)$ & $66.50^{\star \star}$ \\
\hline & $\mathrm{MR}^{\mathrm{b}}$ & $95.69_{a}$ & $145.19_{b}$ & $173.32_{b}$ & $201.64_{b}$ & \\
\hline \multirow[t]{2}{*}{ IPO reality testing } & $M(S D)$ & $1.19(0.30)$ & $1.22(0.21)$ & $1.43(0.58)$ & $1.71(0.50)$ & $28.59^{\star \star}$ \\
\hline & $\mathrm{MR}^{\mathrm{b}}$ & $110.59_{a}$ & $131.88_{a b}$ & $147.50_{b}$ & $204.64_{c}$ & \\
\hline \multirow[t]{2}{*}{ SWLSa } & $M(S D)$ & $5.76(0.90)$ & $5.11(0.94)$ & $4.25(1.11)$ & $3.31(1.42)$ & $86.14^{\star \star}$ \\
\hline & $\mathrm{MR}^{\mathrm{b}}$ & $161.38_{a}$ & $113.34 b$ & $67.90_{\mathrm{C}}$ & $42.00_{c}$ & \\
\hline \multirow[t]{2}{*}{ RSES ${ }^{a}$} & $M(S D)$ & $3.49(0.39)$ & $3.09(0.40)$ & $2.57(0.54)$ & $2.33(0.47)$ & $100.44^{\star \star}$ \\
\hline & $\mathrm{MR}^{\mathrm{b}}$ & $167.50_{\mathrm{a}}$ & $105.71_{a b}$ & $70.58 b$ & $30.57_{c}$ & \\
\hline
\end{tabular}

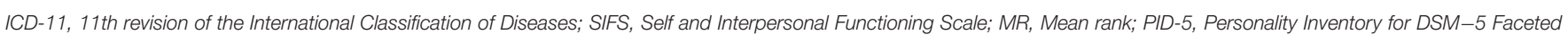
Brief Form (100 items); IPO, Brief 19-item version of the Inventory of Personality Organization; SWLS, Satisfaction with Life Scale; RSES, Rosenberg Self-Esteem Scale.

a Higher scores denote better functioning. For all other variables, higher scores denote more severe pathology.

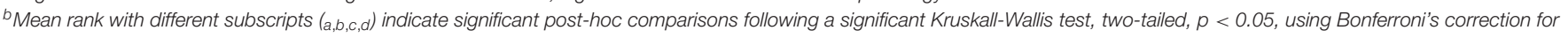
multiple comparisons.

${ }^{c}$ Mean rank not shown in the absence of significant contrasts.

${ }^{*} p<0.01 ;{ }^{* *} p<0.001$.

reluctance of some clinicians to diagnose $\mathrm{PD}$, as it is often perceived as difficult, time-consuming, and off-putting [e.g., (29, 77)]. Indeed, the empirically-based anchors presented in this study are straightforward in their interpretation, which is likely to make them appealing for screening purposes to many clinicians irrespective of their PD assessment expertise. In addition, the SIFS provides an opportunity to assess personality pathology in a way that bridges the North American and European emerging conceptualizations of PD severity, with self and interpersonal deficits at their core. In order to rule on the validity of the proposed anchor points, future studies should focus on their usefulness to guide intensity of clinical treatment and to predict treatment course (13).

\section{DATA AVAILABILITY STATEMENT}

The datasets presented in this article are not readily available because Ethics approval did not include sharing of the 
dataset for the present research. Upon reasonable request, the dataset could be shared, contingent upon the approval of an amendment by ethics committees that authorized the present research. Requests to access the datasets should be directed to dominick.gamache@uqtr.ca.

\section{ETHICS STATEMENT}

The studies involving human participants were reviewed and approved by Ethics committees from the Université du Québec at Trois-Rivières, the Université Laval, the Integrated University Health and Social Services Center of the Capitale-Nationale Sectoral Research Ethics Committee in Neurosciences and Mental Health, and the Integrated University Health and Social Services Center of the Mauricie-et-du-Centre-du-Québec. The patients/participants provided their written informed consent to participate in this study.

\section{AUTHOR CONTRIBUTIONS}

DG and CS designed the study, drafted the first version of the manuscript, analyzed, and interpreted the data. CS drafted the grant proposals that secured financing for the study with the contribution of DG, NB, and MT. CS, NB, and RL drafted the ethics approval demands with the contribution of DG. CS, $\mathrm{PL}, \mathrm{MP}, \mathrm{ML}, \mathrm{KM}, \mathrm{M}-\mathrm{CN}$, and MT made substantial contributions to data acquisition. PL, NB, AC, JF, RL, KM, and M-CN made substantial revisions to the original draft. All authors have read the manuscript and have approved its submission in the present form.

\section{REFERENCES}

1. Hopwood CJ, Kotov R, Krueger RF, Watson D, Widiger TA, Althoff RR, et al. The time has come for dimensional personality disorder diagnosis. Personal Ment Health. (2018) 12:82-6. doi: 10.1002/pmh.1408

2. Krueger RF. Personality disorders are the vanguard of the post-DSM-5.0 era. Personal Disord. (2013) 4:355-62. doi: 10.1037/per0000028

3. Krueger RF, Markon KE. The role of the DSM-5 personality trait model in moving toward a quantitative and empirically based approach to classifying personality and psychopathology. Annu Rev Clin Psychol. (2014) 10:477-501. doi: 10.1146/annurev-clinpsy-032813-153732

4. Tyrer P, Mulder R, Kim YR, Crawford MJ. The development of the ICD-11 classification of personality disorders: an amalgam of science, pragmatism, and politics. Annu Rev Clin Psychol. (2019) 15:481-502. doi: 10.1146/annurev-clinpsy-050718-095736

5. Widiger TA, Trull TJ. Plate tectonics in the classification of personality disorder: shifting to a dimensional model. Am Psychol. (2007) 62:71-83. doi: 10.1037/0003-066X.62.2.71

6. Eysenck HJ. A dimensional system of psychodiagnostics. In: Mahrer AR, editor. New Approaches to Personality Classification. New York, NY: Columbia University Press (1970). p. 169-207.

7. Tyrer P, Alexander J. Classification of personality disorder. Br J Psychiatry. (1979) 135:163-67. doi: 10.1192/bjp.135.2.163

8. Widiger TA, Frances A. The DSM-III personality disorders: perspectives from psychology. Arch Gen Psychiatry. (1985) 42:615-23. doi: 10.1001/archpsyc.1985.01790290097011

\section{FUNDING}

This research was supported by research grants from the Social Sciences and Humanities Research Council of Canada to $\mathrm{CS}, \mathrm{NB}$, and DG for projects entitled A computer-based assessment procedure to improve services accessibility and to establish profiles of clients with dysfunctional personality traits (4A Partnership Engage Grant 2017, Grant number 892-20173003) and Documenting the psychological, relational and sexual functioning of adults and couples consulting in private clinics using a computerized assessment procedure (2A Partnership Engage Grant 2019-20, Grant number 892-2019-1022). It was also financially supported by a sponsorship granted to CS, DG, and MT by the Integrated University Health and Social Services Center of the Capitale-Nationale, Quebec City, Canada.

\section{ACKNOWLEDGMENTS}

We gratefully thank Evens Villeneuve, Renée-Claude Dompierre, Marie-Audrey Lavoie, and the clinical team at the Centre de traitement le Faubourg Saint-Jean (Sample 1), the clinical teams from the Centre de psychologie Québec and the Clinique de psychologie du couple (Sample 3), and Julia Garon-Bissonnette, Élodie Martel, Gabrielle Duguay, and Mathilde Loiselle (Sample 4) for their invaluable contribution to data collection.

\section{SUPPLEMENTARY MATERIAL}

The Supplementary Material for this article can be found online at: https://www.frontiersin.org/articles/10.3389/fpsyt. 2021.628057/full\#supplementary-material

9. American Psychiatric Association. Diagnostic and Statistical Manual of Mental Disorders 5th Edition (DSM-5). Arlington, TX: American Psychiatric Publishing, Inc. (2013).

10. Bender DS, Morey LC, Skodol AE. Toward a model for assessing level of personality functioning in DSM-5, part I: a review of theory and methods. J Pers Assess. (2011) 93:332-46. doi: 10.1080/00223891.2011. 583808

11. Krueger RF, Eaton NR, Derringer J, Markon KE, Watson D, Skodol AE. Personality in DSM-5: helping delineate personality disorder content and framing the metastructure. J Pers Assess. (2011) 93:325-31. doi: 10.1080/00223891.2011.577478

12. Zimmermann J, Kerber A, Rek K, Hopwood C, Krueger R. A brief but comprehensive review of research on the alternative DSM-5 model for personality disorders. Curr Psychiatry Rep. (2019) 21:1-19. doi: 10.1007/s11920-019-1079-Z

13. Bach B, First MB. Application of the ICD-11 classification of personality disorders. BMC Psychiatry. (2018) 18:351. doi: 10.1186/s12888-018-1908-3

14. World Health Organization. ICD-11, the 11th Revision of the International Classification of Diseases. (2020). Available online at: https://www.who.int/ classifications/icd/en/ (accessed October 4, 2020).

15. Bach B, Anderson JL. Patient-reported ICD-11 personality disorder severity and DSM-5 level of personality functioning. J Personal Disord. (2018) 34:23949. doi: 10.1521/pedi_2018_32_393

16. Herpertz SC, Huprich SK, Bohus M, Chanen A, Goodman M, Lehnum L, et al. The challenge of transforming the diagnostic system of personality disorders. J Pers Disord. (2017) 31:577-89. doi: 10.1521/pedi_2017_31_338 
17. Bastiaansen L, De Fruyt F, Rossi G, Schotte C, Hofmans J. Personality disorder dysfunction versus traits: structural and conceptual issues. Personal Disord. (2013) 4:293-303. doi: 10.1037/per0000018

18. Buer Christensen T, Eikenaes I, Hummelen B, Pedersen G, Nysæter TE, Bender DS, et al. Level of personality functioning as a predictor of psychosocial functioning-concurrent validity of Criterion A. Personal Disord. (2020) 11:79-90. doi: 10.1037/per0000352

19. Clark LA, Nuzum H, Ro E. Manifestations of personality impairment severity: comorbidity, course/prognosis, psychosocial dysfunction, and 'borderline' personality features. Curr Opin Psychol. (2018) 21:117-21. doi: 10.1016/j.copsyc.2017.12.004

20. Hopwood CJ, Malone JC, Ansell EB, Sanislow CA, Grilo CM, McGlashan $\mathrm{TH}$, et al. Personality assessment in DSM-5: empirical support for rating severity, style, and traits. J Personal Disord. (2011) 25:305-20. doi: 10.1521/pedi.2011.25.3.305

21. Sharp C, Wright AGC, Fowler JC, Frueh BC, Allen JG, Oldham J, et al. The structure of personality pathology: both general ('g') and specific ('s') factors? J Abnorm Psychol. (2015) 124:387-98. doi: 10.1037/abn0000033

22. Wright AGC, Hopwood CJ, Skodol AE, Morey LC. Longitudinal validation of general and specific structural features of personality pathology. J Abnorm Psychol. (2016) 125:1120-34. doi: 10.1037/abn0000165

23. Crawford MJ, Koldobsky N, Mulder R, Tyrer P. Classifying personality disorder according to severity. J Personal Disord. (2011) 25:321-30. doi: 10.1521/pedi.2011.25.3.321

24. Quilty LC, Bagby RM, Krueger RF, Pollock BG. Validation of DSM- 5 clinicianrated measures of personality pathology. Psychol Assess. (2020) 33:84-9. doi: $10.1037 /$ pas 0000960

25. Waugh $\mathrm{MH}$, McClain CM, Mariotti EC, Mulay AL, DeVore EN, Lenger KA, et al. Comparative content analysis of self-report scales for level of personality functioning. J Pers Assess. (2020) 103:161-73. doi: 10.1080/00223891.2019.1705464

26. Olajide K, Munjiza J, Moran P, O'Connell L, Newton-Howes G, Bassett P, et al. Development and psychometric properties of the standardized assessment of severity of personality disorder (SASPD). J Personal Disord. (2018) 32:44-56. doi: 10.1521/pedi_2017_31_285

27. McCabe GA, Widiger TA. A comprehensive comparison of the ICD-11 and DSM-5 section III personality disorder models. Psychol Assess. (2020) 32:72-84. doi: $10.1037 /$ pas0000772

28. Hutsebaut J, Feenstra DJ, Kamphuis JH. Development and preliminary psychometric evaluation of a brief self-report questionnaire for the assessment of the DSM-5 level of personality functioning scale: The LPFS brief form (LPFS-BF). Personal Disord. (2016) 7:192-7. doi: 10.1037/per0000159

29. Rek K, Thielmann I, Henkel M, Crawford M, Piccirilli L, Graff A, et al. A psychometric evaluation of the standardized assessment of severity of personality disorder (SASPD) in nonclinical and clinical German samples. Psychol Assess. (2020) 32:984-90. doi: 10.1037/pas0000926

30. Gamache D, Savard C, Leclerc P, Côté A. Introducing a short self-report for the assessment of DSM-5 level of personality functioning for personality disorders: the self and interpersonal functioning scale. Personal Disord. (2019) 10:438-47. doi: 10.1037/per0000335

31. Clark LA, Nuzum H, Shapiro JL, Vanderbleek EN, Daly EJ, Simons AD, et al. Personality profiles as potential targets for intervention: identification and replication. Personal Ment Health. (2020) 14:142-63. doi: 10.1002/pmh.1455

32. Paris J. Stepped care for Borderline Personality Disorder: Making Treatment Brief, Effective, and Accessible. Cambridge, MA: Academic Press (2017).

33. Maples JL, Carter NT, Few LR, Crego C, Gore WL, Samuel DB, et al. Testing whether the DSM-5 personality disorder trait model can be measured with a reduced set of items: an item response theory investigation of the personality inventory for DSM-5. Psychol Assess. (2015) 27:1195-210. doi: $10.1037 /$ pas 0000120

34. Roskam I, Galdiolo S, Hansenne M, Massoudi K, Rossier J, Gicquel L, et al. The psychometric properties of the French version of the personality inventory for DSM-5. PLoS ONE. (2015) 10:e0133413. doi: 10.1371/journal.pone.0133413

35. Krueger RF, Derringer J, Markon K, Watson D, Skodol AE. The Personality Inventory for DSM5 Brief Form (PID-5-BF). American Psychiatric Association (2013). Available online at: https://www.psychiatry.org/File\%20Library/ Psychiatrists/Practice/DSM/APA_DSM5_The-Personality-Inventory-ForDSM-5-Brief-Form-Adult.pdf (accessed October 4, 2020).
36. Combaluzier S, Gouvernet B, Menant F, Rezrazi A. Validation d'une version française de la forme brève de l'inventaire des troubles de la personnalité pour le DSM-5 (PID-5 BF) de Krueger [Validation of a French translation of Krueger's personality inventory for DSM- 5 in its brief form (PID-5 BF)] [published correction appears in Encephale. (2019). 45:535]. Encephale. (2018) 44:9-13. doi: 10.1016/j.encep.2016.07.006

37. Bohus M, Kleindienst N, Limberger MF, Stieglitz R-D, Domsalla M, Chapman $\mathrm{AL}$, et al. The short version of the Borderline Symptom List (BSL-23): development and initial data on psychometric properties. Psychopathology. (2009) 42:32-9. doi: 10.1159/000173701

38. Nicastro R, Prada P, Kung A-L, Salamin V, Dayer A, Aubry J-M, et al. Psychometric properties of the French borderline symptom list, short form (BSL-23). Borderline Personal Disord Emot Dysregul. (2016) 3:4. doi: 10.1186/s40479-016-0038-0

39. Schoenleber M, Roche MJ, Wetzel E, Pincus AL, Roberts BW. Development of a brief version of the pathological narcissism inventory. Psychol Assess. (2015) 27:1520-6. doi: 10.1037/pas0000158

40. Diguer L, Turmel, V, Brin J, Lapointe T, Chrétien S, Marcoux L-A, et al. Traduction et validation en Français du pathological narcissism inventory [Translation and validation in French of the pathological narcissism inventory]. Can J Behav Sci. (2020) 52:115-20. doi: 10.1037/cbs0000140

41. Bryant FB, Smith BD. Refining the architecture of aggression: a measurement model for the buss-perry aggression questionnaire. J Res Pers. (2001) 35:13867. doi: 10.1006/jrpe.2000.2302

42. Buss AH, Perry M. The aggression questionnaire. J Pers Soc Psychol. (1992) 63:452-9. doi: 10.1037//0022-3514.63.3.452

43. Genoud PA, Zimmermann G. French Version of the 12-Item Aggression Questionnaire: Preliminary Psychometric Properties. Neuchâtel: Poster Presented at the 11th Congress of the Swiss Psychological Society. (2009).

44. Davis MH. Measuring individual differences in empathy: evidence for a multidimensional approach. J Pers Soc Psychol. (1983) 44:113-26. doi: 10.1037/0022-3514.44.1.113

45. Gilet A-L, Mella N, Studer J, Grühn D, Labouvie-Vief G. Assessing dispositional empathy in adults: a French validation of the interpersonal reactivity index (IRI). Can J Behav Sci. (2013) 45:42-8. doi: 10.1037/ a0030425

46. Patton JH, Stanford MS, Barratt ES. Factor structure of the Barratt impulsiveness scale. J Clin Psychol. (1995) 51:768-74. doi: 10.1002/1097-4679(199511)51:6<768::aid-jclp2270510607>3.0.co;2-1

47. Baylé FJ, Lôo H, Caci H, Adés J, Chignon J-M, Gorwood P, et al. Structure factorielle de la traduction française de l'Échelle d'impulsivité de Barratt (BIS-10) [Factor structure of the French version of the Barratt impulsiveness scale-10]. Can J Psychiatry. (2000) 45:156-65. doi: 10.1177/070674370004 500206

48. Ilfeld FW. Psychologic status of community residents along major demographic dimensions. Arch Gen Psychiatry. (1978) 35:716-24. doi: 10.1001/archpsyc. 1978.01770300058006

49. Préville M, Boyer R, Potvin L, Perreault C, Légaré G. La détresse psychologique: détermination de la fiabilité et de la validité de la mesure utilisée dans l'enquête Santé Québec 87 [Psychological distress: determining the reliability and validity of the measure used in the Santé Québec survey 87]. In: Les Cahiers de Recherche no 7. Gouvernement du Québec, Ministère de la Santé et des services sociaux du Québec. (1992). Available online at: http://www.santecom.qc.ca/Bibliothequevirtuelle/ santecom/35567000006905.pdf (accessed October 4, 2020).

50. Lafontaine M-F, Brassard A, Lussier Y, Valois P, Shaver PR, Johnson SM. Selecting the best items for a short-form of the experiences in close relationships questionnaire. Eur J Psychol Assess. (2015) 32:140-54. doi: 10.1027/1015-5759/a000243

51. Kessler RC, Andrews G, Colpe LJ, Hiripi E, Mroczek DK, Normand SL, et al. Short screening scales to monitor population prevalences and trends in non-specific psychological distress. Psychol Med. (2002) 32:959-76. doi: $10.1017 / \mathrm{s} 0033291702006074$

52. Gravel R, Connolly D, Bédard M. Enquête sur la Santé des Collectivités Canadiennes (ESCC): Santé Mentale et Bien-être, Cycle 2.1. [Canadian Community Health Survey (CCHS): Mental Health and Well-being, Cycle 2.1]. (2020). Available online at: https://www.stat.gouv.qc.ca/enquetes/sante/ escc.html (accessed October 4, 2020). 
53. Cox JL, Holden JM, Sagovsky R. Detection of postnatal depression. Development of the 10-item Edinburgh postnatal depression scale. $\mathrm{Br} J$ Psychiatry. (1987) 150:782-6. doi: 10.1192/bjp.150.6.782

54. Adouard F, Glangeaud-Freudenthal NM, Golse B. Validation of the Edinburgh postnatal depression scale (EPDS) in a sample of women with highrisk pregnancies in France. Arch Womens Ment Health. (2005) 8:89-95. doi: 10.1007/s00737-005-0077-9

55. Watson D, Clark LA, Tellegen A. Development and validation of brief measures of positive and negative affect: the PANAS scales. J Pers Soc Psychol. (1988) 54:1063-70. doi: 10.1037//0022-3514.54.6.1063

56. Gaudreau P, Sanchez X, Blondin J-P. Positive and negative affective states in a performance-related setting: testing the factorial structure of the PANAS across two samples of French-Canadian participants. Eur J Psychol Assess. (2006) 22:240-9. doi: 10.1027/1015-5759.22.4.240

57. Bernstein EM, Putnam FW. Development, reliability, and validity of a dissociation scale. J Nerv Ment Dis. (1986) 174:727-35. doi: 10.1097/00005053-198612000-00004

58. Larøi F, Billieux J, Defeldre A-C, Ceschi G, Van der Linden M. Factorial structure and psychometric properties of the French adaptation of the dissociative experiences scale (DES) in non-clinical participants. Eur Rev Appl Psychol. (2013) 63:203-8. doi: 10.1016/j.erap.2013.04.004

59. Wilkins KC, Lang AJ, Norman SB. Synthesis of the psychometric properties of the PTSD checklist (PCL) military, civilian, and specific versions. Depress Anxiety. (2011) 28:596-606. doi: 10.1002/da.20837

60. Ashbaugh AR, Houle-Johnson S, Herbert C, El-Hage W, Brunet A. Psychometric validation of the English and French versions of the posttraumatic stress disorder checklist for DSM-5 (PCL-5). PLoS ONE. (2016) 11:e0161645. doi: 10.1371/journal.pone.0161645

61. Verreault M, Sabourin S, Lussier Y, Normandin L, Clarkin JF. Assessment of personality organization in couple relationships: factorial structure of the inventory of personality organization and incremental validity over neuroticism. J Pers Assess. (2013) 95:85-95. doi: 10.1080/00223891.2012.713883

62. Kernberg OF, Clarkin JF. The Inventory of Personality Organization. White Plains, NY: The New York Hospital-Cornell Medical Center (1995).

63. Diener E, Emmons RA, Larsen RJ, Griffin S. The satisfaction with life scale. J Pers Assess. (1985) 49:71-5. doi: 10.1207/s15327752jpa4901_13

64. Blais MR, Vallerand RJ, Pelletier LG, Brière NM. Léchelle de satisfaction de vie: validation canadienne-française du "satisfaction with life scale" [The Satisfaction Scale: French-Canadian validation of the Satisfaction with Life Scale]. Can J Behav Sci. (1989) 21:210-23.

65. Rosenberg M. Society and the Adolescent Self-Image. Princeton, NJ: Princeton University Press (1965).

66. Vallières EF, Vallerand RJ. Traduction et validation canadienne-française de l'Échelle de l'estime de soi de Rosenberg [French-Canadian translation and validation of the Rosenberg Self-Esteem Scale]. Int J Psychol. (1990) 25:305-16. doi: 10.1080/00207599008247865

67. Morgan TA, Zimmerman M. Epidemiology of personality disorders. In: Livesley WJ, Larstone R, editors. Handbook of Personality Disorders: Theory,
Research, and Treatment 2nd ed. New York, NY: The Guilford Press (2018). p. 173-96.

68. Coid J, Yang M, Tyrer P, Roberts A, Ullrich S. Prevalence and correlates of personality disorder in Great Britain. Br J Psychiatry. (2006) 188:423-31. doi: 10.1192/bjp.188.5.423

69. Black DW, Noyes R Jr, Pfohl B, Goldstein RB, Blum N. Personality disorder in obsessive-compulsive volunteers, well comparison subjects, and their first-degree relatives. Am J Psychiatry. (1993) 150:1226-32. doi: 10.1176/ajp.150.8.1226

70. Hallquist MN, Pilkonis PA. Refining the phenotype of borderline personality disorder: diagnostic criteria and beyond. Personal Disord. (2012) 3:228-46. doi: 10.1037/a0027953

71. Markon KE, Krueger RF. Information-theoretic latent distribution modeling: distinguishing discrete and continuous latent variable models. Psychol Methods. (2006) 11:228-43. doi: 10.1037/1082-989X.11. 3.228

72. Rice ME, Harris GT. Comparing effect sizes in follow-up studies: ROC Area, Cohen's d, and r. Law Hum Behav. (2005) 29:615-20. doi: 10.1007/s10979-005-6832-7

73. Muthén LK, Muthén BO. Mplus: Statistical Analysis With Latent Variables. Los Angeles, CA (2019).

74. Samuel DB, Suzuki T, Bucher MA, Griffin SA. The agreement between clients' and their therapists' ratings of personality disorder traits. J Consult Clin Psychol. (2018) 86:546-55. doi: 10.1037/ccp00 00304

75. Stanton K, Brown MFD, Bucher MA, Balling C, Samuel DB. Selfratings of personality pathology: insights regarding their validity and treatment utility. Curr Treat Options Psychiatry. (2019) 6:299-311. doi: 10.1007/s40501-019-00188-6

76. Grant BF, Hasin DS, Stinson FS, Dawson DA, Chou SP, Ruan WJ, et al. Prevalence, correlates, and disability of personality disorders in the United States: results from the national epidemiologic survey on alcohol and related conditions. J Clin Psychiatry. (2004) 65:948-58. doi: $10.4088 /$ jcp.v65n0711

77. Paris J. Why psychiatrists are reluctant to diagnose: borderline personality disorder. Psychiatry. (2007) 4:35-9.

Conflict of Interest: The authors declare that the research was conducted in the absence of any commercial or financial relationships that could be construed as a potential conflict of interest.

Copyright (c) 2021 Gamache, Savard, Leclerc, Payant, Berthelot, Côté, Faucher, Lampron, Lemieux, Mayrand, Nolin and Tremblay. This is an open-access article distributed under the terms of the Creative Commons Attribution License (CC BY). The use, distribution or reproduction in other forums is permitted, provided the original author(s) and the copyright owner(s) are credited and that the original publication in this journal is cited, in accordance with accepted academic practice. No use, distribution or reproduction is permitted which does not comply with these terms. 